\title{
Rare and Interesting Case Report of Bilateral Congenital Corneal Dystrophy with Associated Left Eye Anterior Staphyloma
}

\author{
Gowhar Ahmad* \\ Department of ophthalmology, University of Jammu and Kashmir, India \\ *Corresponding author: Gowhar Ahmad, Department of ophthalmology, University of Jammu and Kashmir, India. \\ Submission: 監 January 29, 2018; Published: 眥 April 13, 2018
}

\section{Introduction}

Corneal dystrophy is a very rare cong entity with probable deposition of some unknown material in corneal stroma of an unknown etiology with strong heredo-familial tendency a better modality of defining corneal dystrophy is as follows lesions in the cornea of an unknown etiology which may manifest either at birth or at 1st or 2nd decade of life. May remain stationary or progressive has got a strong heredo familial tendency. Clinically a bilateral central symmetrical corneal opacity with impaired corneal sensations and absence of deep vascularisation is corneal dystrophy unless proved otherwise the other associated cong anamolies with bil cong dystrophy are very rare they are in the form of
a) Cong glaucoma
b) Keratoconus
c) Ant staphyloma
d) Cong absence of desmets membrane
e) Ched
f) Deafness known as cogans syndrome
g) Kc sicca
h) Medulated optic nerve fibers
i) Cong ptosis
j) Conjuctival xerosis

Keywords: Cong glaucoma; Keratoconus; Ant Staphyloma; Desmets Membrane; Ched; Deafness; Cogans Syndrome; Kc Sicca; Medulated Optic Nerve Fibers; Cong Ptosis; Conjuctival Xerosis; Micocephaly; Icthyosis; Staphyloma; Ultrasonub; Dystrophy; Keratoplasty; Spina Bi-fida; Retina; Cong Anamolies; Corneal Stroma

\section{Obstetric History}

A first married cousin first pregnancy in the first trimester of pregnancy ultrasound revealed a male fotus with spina bi-fida and microcephaly so the pregnancy was terminated $2^{\text {nd }}$ pregnancy $\mathrm{Ft}$ delivered normal female child after l s c s alive 9 years of age no associated cong disorders $3^{\text {rd }} \mathrm{f} \mathrm{t}$ male child delivered after l s c s died after 3 days due to generalized icthyosis $4^{\text {th }} \mathrm{Ft}$ female child delivered after l s s c had bil cong corneal dystrophy with left eye associated ant staphyloma with no other associated abnormalities seen at 24 hours of age IOP measured with tono pen was normal b scan ultrasound showed attached retina [1].

\section{Case Report}

This baby at age of 3 months under went right eye modified keratoplasty and at 3 years of age left eye cosmotic kerato prosthesis was done.

\section{Discussion}

It is very important to encourage parents of such patients who are very much depressed.

\section{Conclusion}

This female child is at present 5 years of age very active and intelligent goes to play school sees well with her $\mathrm{r}$ eye even is able to operate mobile phone and Tablet PC very efficiently bil cong dystrophy with associated cong disorders are very rare could only find $[2,3]$ references cases in literature one case of bil cong corneal dystrophy with deafness was reported in King Khaled Eye specialist hospital Reyadh K.S.A $2^{\text {nd }}$ patient of bil cong corneal dystrophy with rt. eye glaucoma has been reported in R.P center for ophthalmic sciences A.I.M.S, New Delhi, India. 3rd case of malignant melanoma of choroid has been reported in PGI Chandigarh. So my reported case is probably in literature [4-6].

\section{References}

1. Bhat YR, Sanoj KM (2005) Images in clinical practices sclerocornea indian paediatrics. p. 42 .

2. Hand CK (1999) Harmondl kennedy sm fitzSimon js collum lm parfrey na localisation of the gene for autosomal recessive cong heeditary endothelial dystrophy ched2 to chrosome 20 by homozy gosity Mapping genomics 1(6): 111. 
3. (2003) Medine 4 miler $\mathrm{mm}$ butrus $\mathrm{s}$ hidayat a wei $\mathrm{l} \mathrm{l}$ pontigo $\mathrm{m}$ corneoscleral transplantation in cong corneal staphyloma and peters. Anamoly Ophthalmic Genet 1(59): 83.

4. Desir J, Abramowicz M (2008) Cong hereditary endothelial dystrophy with progressive sensorineural deafness (Harboyan Syndrome) Orphanet J Rare Dis 15(3): 28.
5. Waizenegger UR, Kohnen T, Weidle EG, Schutte E (1995) Cong familial cornea plana with ptosis Peripheral sclerocornea and conjuctival xerosis klin monatsbl augenheilkd 7(2): 111.

6. Medline Perry HD, Cameron JD. Cong Corneal Opacities. (c) (i) Creative Commons Attribution 4.0

For possible submissions Click Here
Submit Article

\section{MSOR Medral \& \\ Medical \& Surgical Ophthalmology Research} Ophithalmoloor

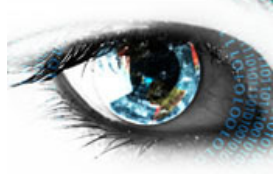

\section{Benefits of Publishing with us}

- High-level peer review and editorial services

- Freely accessible online immediately upon publication

- Authors retain the copyright to their work

- Licensing it under a Creative Commons license

- Visibility through different online platforms 